\title{
Nanotoxicology of Dendrimers in the Mammalian
} Heart: ex vivo and in vivo Administration of $\mathrm{G} 6$ PAMAM Nanoparticles Impairs Recovery of Cardiac Function Following Ischemia-Reperfusion Injury

This article was published in the following Dove Press journal:

International Journal of Nanomedicine

\section{Fawzi Babiker (iD) \\ Ibrahim F Benter ${ }^{2}$ \\ Saghir Akhtar $\mathbb{D B}^{3}$}

'Department of Physiology, Faculty of Medicine, Health Science Center, Kuwait University, Kuwait City, Kuwait; ${ }^{2}$ Faculty of Medicine, Eastern Mediterranean University, Famagusta, North Cyprus, Republic of Cyprus; ${ }^{3}$ College of Medicine, QU Health, Qatar University, Doha, Qatar
Correspondence: Fawzi Babiker Department of Physiology, Faculty of Medicine, Health Science Center, Kuwait University, PO Box 24923, Safat 13110, Kuwait,

Tel +96524636360

Fax +96525338937

Email Fawzi.b@hsc.edu.kw

Saghir Akhtar

College of Medicine, QU Health, Qatar University, PO Box 27I3, Doha, Qatar

Tel +974-4403 7865

Email s.akhtar@qu.edu.qa
Aim: The effects of polyamidoamine (PAMAM) dendrimers on the mammalian heart are not completely understood. In this study, we have investigated the effects of a sixth-generation cationic dendrimer (G6 PAMAM) on cardiac function in control and diabetic rat hearts following ischemia-reperfusion (I/R) injury.

Methods: Isolated hearts from healthy non-diabetic (Ctr) male Wistar rats were subjected to ischemia and reperfusion (I/R). LV contractility and hemodynamics data were computed digitally whereas cardiac damage following $\mathrm{I} / \mathrm{R}$ injury was assessed by measuring cardiac enzymes. For ex vivo acute exposure experiments, G6 PAMAM was administered during the first 10 mins of reperfusion in $\mathrm{Ctr}$ animals. In chronic in vivo studies, nondiabetic rats (Ctr) received either vehicle or daily i.p. injections of G6 PAMAM (40 mg/kg) for 4 weeks. Diabetic (D) animals received either vehicle or daily i.p. injections of G6 PAMAM (10, 20 or $40 \mathrm{mg} / \mathrm{kg}$ ) for 4 weeks. The impact of G6 PAMAM on pacing-postconditioning (PPC) was also studied in Ctr and D rats.

Results: In ex vivo studies, acute administration of G6 PAMAM to isolated Ctr hearts during reperfusion dose-dependently impaired recovery of cardiac hemodynamics and vascular dynamics parameters following I/R injury. Chronic daily i.p. injections of G6 PAMAM significantly $(\mathrm{P}<0.01)$ impaired recovery of cardiac function following $\mathrm{I} / \mathrm{R}$ injury in nondiabetic animals but this was not generally observed in diabetic animals except for CF which was impaired by about 50\%. G6 PAMAM treatment completely blocked the protective effects of PPC in the Ctr animals.

Conclusion: Acute ex vivo or chronic in vivo treatment with naked G6 PAMAM dendrimer can significantly compromise recovery of non-diabetic hearts from $\mathrm{I} / \mathrm{R}$ injury and can further negate the beneficial effects of PPC. Our findings are therefore extremely important in the nanotoxicological evaluation of G6 PAMAM dendrimers for potential clinical applications in physiological and pathological settings.

Keywords: PAMAM, postconditioning, diabetes, ischemia, reperfusion

\section{Background}

Currently, there is a growing interest in the use of hyperbranched, cationic polyamidoamine (PAMAM) dendrimer nanoparticles in the delivery of therapeutic compounds to diseased cells. $^{1-4}$ These polymeric nanostructures are unique in that their synthesis can be controlled to produce spherical branched-like architectures (dendrimers) with defined molecular size and surface properties. ${ }^{1-4}$ PAMAM dendrimers can be engineered to 
possess cationic amine surface groups that allow binding of negatively charged drugs and nucleic acids (eg, plasmid DNA, siRNAs, oligonucleotides) to enhance their uptake and delivery into targeted cells ${ }^{1-4}$ by endocytosis or via membrane pore formation. ${ }^{5,6}$ PAMAM dendrimers have been examined for their use as delivery vehicles for genes to target host cells for the treatment of a variety of diseases. ${ }^{4}$ Despite the wide use of PAMAM dendrimers in research and drug delivery, there is evidence that they may exert biological actions of their own that could lead to toxicological adverse effects. ${ }^{1-4,7-11}$ PAMAM dendrimer-mediated cell toxicity in vitro is dependent on the surface chemistry and molecular weight (or generation) in vitro. ${ }^{2,11}$ However, in vivo studies with cationic PAMAM dendrimers suggest that safe use of these polymer structures is possible, depending on the route and dose administered. $^{10,12}$ Indeed, we have recently shown that chronic, repeated i.p. administration of PAMAM dendrimers in an animal model of diabetes led to a significant correction in diabetes-induced vascular remodeling and dysfunction. ${ }^{10}$ However, the effects of PAMAM dendrimers on the functioning of the healthy and pathological heart in animal models are not known. In this study, we aim to investigate the effect of a G6 cationic PAMAM dendrimer nanoparticles on cardiac function in normal and diabetic hearts.

Coronary heart disease (CHD), is one of the major causes of morbidity and mortality in the world. ${ }^{13}$ The lethal type of CHD occurs due to the occlusion of the coronary artery by an atherosclerotic plaque, leading to acute inadequate blood flow and oxygen supply to heart which leads to acute myocardial infarction (AMI). ${ }^{14}$ AMI is the major cause of morbidity and mortality among ischemic heart diseases. ${ }^{15}$ Several methods like thrombolytics, percutaneous coronary intervention (PCI) and coronary artery bypass grafting (CABG) have been successfully used in reducing AMI size and patients' mortality. ${ }^{16}$ However, these techniques are associated with reperfusion injury which is created by the revascularization. ${ }^{17}$

Several methods of myocyte protection have been attempted to salvage the myocardium from reperfusion injury. ${ }^{18-22}$ These procedures were proven to attenuate oxidative stress, ${ }^{20,23}$ reduce apoptosis and necrosis, ${ }^{24,25}$ prevent the opening of mitochondrial permeability transition pore (mPTP) at early phase of reperfusion, ${ }^{26}$ save myocytes and normalize heart function. ${ }^{18,20,22,27,28}$ Among these procedures, postconditioning provided protection to the myocardium ${ }^{19}$ and attenuates apoptosis, necrosis, endothelial dysfunction, ROS formation as well as reperfusion arrhythmias. ${ }^{29}$ The application of postconditioning after ischemia and after myocyte injury has occurred, makes it a potentially promising procedure for the clinic that is likely to be preferred by many surgeons compared to other procedures. However, recently postconditioning started to lose its popularity because of the disappointing results obtained when this procedure was translated to the clinic. $^{30-32}$ Pharmacological conditioning of the heart was also employed and provided cardiac protection similar to that provided by classical postconditioning. ${ }^{27,28,33}$ Adenosine agonists, for example, have improved myocardial perfusion and reduced infarction when administered intravenously at the time of reperfusion. ${ }^{34,35}$ Opioids such as morphine showed ability to reduce $\mathrm{AMI}$ and attenuate ischemia/reperfusion (I/R) injury when applied at the time of reperfusion..$^{33,35,36}$ Furthermore, bradykinin administration at early reperfusion showed ability to protect the heart and reduce infarct size, while administration of bradykinin antagonists abolished the cardiac protection induced by postconditioning. ${ }^{27,33,37}$ Volatile anesthetics were shown to protect the heart against reperfusion injury in both in vivo and clinical studies. ${ }^{33,38}$ The intensive studies done to date on these pharmaceutical agents proved that these drugs activate pathways similar to that of postconditioning. ${ }^{27,35,39}$ Although PAMAM dendrimers have recently been reported by us to improve diabetes-induced vascular dysfunction through modulation of key signaling pathways, ${ }^{10}$ little is known about their direct effects on the heart, or on cardiac recovery following I/R injury. In this study, we have investigated the ex vivo and in vivo effects of a sixth-generation cationic (G6) PAMAM dendrimer on recovery of cardiac function in control (healthy non-diabetic) and diabetic rat hearts following $\mathrm{I} / \mathrm{R}$ injury. Furthermore, we also studied the impact of G6 PAMAM dendrimers on pacing-postconditioning (PPC) in control and diabetic rats.

\section{Materials and Methods Drugs and Reagents}

The "as-supplied" G6 PAMAM dendrimer nanoparticles (6.7 $\mathrm{nm}$ diameter, MW of 58,048 and bearing 256 surface amino groups) were synthesised by Dendritech (USA) and acquired from the Sigma Chemical Company (St Louis, MO, USA). Their properties have been previously characterized and appear to be mono-disperse structures (Akhtar et al, 2019). Streptozotocin (STZ) and all other reagents were purchased from Sigma Chemical Company (St Louis, MO, USA).

\section{Experimental Animals}

Male Wistar rats $(250-350 \mathrm{~g})$ were collected from the Animal Resources Center at Kuwait University. All experiments were performed following the approval of the Animal 
Ethics Committee of the Health Science Center, Kuwait University, Kuwait. Animal treatment and handling were in accordance with the International Guide for the Care and Use of Laboratory Animals. All animals were maintained under controlled temperature $\left(21-24^{\circ} \mathrm{C}\right), 12 \mathrm{~h}$ light/dark cycle (light 7 a.m. - 7 p.m.) and humidity (50\%). Animals were housed in plastic cages ( 2 rats/cage) and food and water were available ad libitum.

\section{Induction of Diabetes}

Diabetes was induced as described previously, ${ }^{40}$ using a single intraperitoneal injection of streptozotocin (STZ) $55 \mathrm{mg} / \mathrm{kg}$ body weight. Basal glucose levels were determined prior to STZ injection and $48 \mathrm{~h}$ after STZ injection. Rats with a blood glucose concentration above $250 \mathrm{mg} / \mathrm{dL}$ were declared diabetic and any rats not meeting this criterion were excluded from the study. The animals' diabetic state was re-assessed after 4 weeks just before sacrificing the animals.

\section{Experimental Procedure}

Rats were anesthetized with intramuscular injection of sodium pentobarbital $(60 \mathrm{mg} / \mathrm{kg})$ and anticoagulated with heparin (1000 U/kg body weight) intraperitoneally. The diaphragm was accessed by a transabdominal incision and cut carefully to expose the thoracic cavity. The thorax was opened by a bilateral incision along the lower margin of the chest from the last to first ribs. The thoracic cage was folded back and the heart was exposed and excised. To limit ischemic injury during the time between excision and restoration of vascular perfusion, the heart was directly immersed in a cold $\left(4^{\circ} \mathrm{C}\right) \mathrm{Krebs}-$ Hensleit (KH) solution. ${ }^{41}$

Heart cannulation and perfusion were done using a modified Langendorff setup for the perfused rat heart as described previously. ${ }^{42}$ Briefly, the heart was perfused retrograde with freshly prepared Krebs-Hensleit buffer. The buffer was gassed with a mixture of $\mathrm{O}_{2}(95 \%)$ and $\mathrm{CO}_{2}(5 \%), \mathrm{pH}$ $7.35-7.45$ at $37 \pm 0.5^{\circ} \mathrm{C}$. Myocardial temperature was monitored by a needle thermistor probe (Thermlert TH-5, Physitemp, USA) inserted at the apex of the heart. Pacing electrodes were placed on RA appendage to keep the heart beating at physiological rat heart rate. Regional ischemia was induced by occluding left anterior descending (LAD) coronary artery for $30 \mathrm{~min}$. Preload was kept constant at $6 \mathrm{mmHg}$ under basal controlled conditions and perfusion pressure (PP) was kept constant at $50 \mathrm{~mm} \mathrm{Hg}$ throughout the experimental procedure in all protocols. PP was measured immediately downstream from the flow probe in a branch of the aortic cannula using a Statham pressure transducer (P23 Db). Constant PP was ensured electronically by means of the perfusion assembly (Module PPCM type 671, Hugo Sachs Electronik, Germany).

\section{Study Protocol}

This study was conducted in 3 experimental protocols (Figure 1). Experiment 1 consisted of 24 non-diabetic rats and hearts isolated from these rats were divided equally into 4 groups ( $n=6$ per group). This experiment was designed mainly to check for a possible safe concentration of G6 PAMAM dendrimer following acute, ex vivo administration in isolated control hearts. One group received no treatment and served as the control $(n=6)$ and the other three groups received G6 PAMAM dendrimer in concentration $(0.1,1.0$ and $2 \mu \mathrm{g} / \mathrm{mL}$, respectively) and subjected to reperfusion ( $\mathrm{n}=6$ in each group) (Figure 1)

Experiment two consisted of 24 rats, which were divided into two groups each of nondiabetic $(n=12)$ or diabetic $(n=12)$ rats. One subgroup received only vehicle $(n=6)$ and served as the control and another subgroup $(n=6)$ received daily i.p. injections of G6 PAMAM dendrimer, $40 \mathrm{mg} / \mathrm{kg}$ for 4 weeks and served as a treatment group. Hearts isolated from all animals were subjected to 20 min stabilization followed by 30 min reperfusion with no additional treatment (Figure 1).

Experiment 3 consisted of 48 rats, divided into two groups; nondiabetic group $(n=18)$ and diabetic group $(n=30)$. In this experiment, we wanted to evaluate the effect of chronic, repeated in vivo (i.p) administration of G6 PAMAM dendrimer on the procedures that protect the heart against I/R injury like PPC. The first group (nondiabetic) was further subdivided into three subgroups ( $n=6$ per group). Subgroups 1 and 2 received only vehicle and subgroup 3 ( $n=6$ in each group) received daily i.p. injections of G6 PAMAM dendrimer (40 mg/ $\mathrm{kg}$ ) for 4 weeks. From these, subgroup 1 was subjected to ischemia with no other treatment and served as control, subgroups 2 and 3 were subjected to ischemia and PPC. The second group (diabetic rats) was further subdivided into 5 subgroups $(n=6$ in each subgroup) to illustrate the effect of variable concentrations of the G6 PAMAM dendrimer on the diabetic animals in presence of PPC. Subgroup 1 and 2 ( $n=6$ per subgroup) received only daily i.p. injections of vehicle, subgroups 3,4 and 5 ( $n=6$ per subgroup) received daily i.p. injections of G6 PAMAM dendrimer $(10,20$ or $40 \mathrm{mg} / \mathrm{kg})$ respectively, for 4 weeks. Subgroup 1 was subjected to only ischemia with no other treatment (control group) and subgroup 2 subjected to ischemia and PPC and subgroups 3, 4 and 5 were subjected to ischemia and PPC (Figure 1). All animals were subjected to 30 min reperfusion. 


\section{Experiment 1}

Figure 1

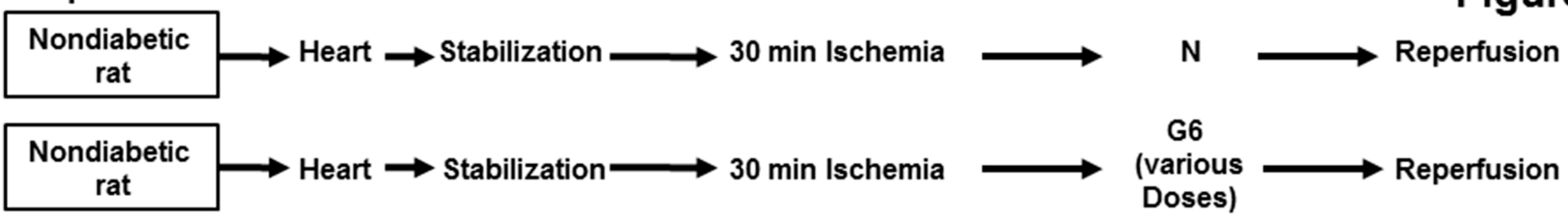

\section{Experiment 2}

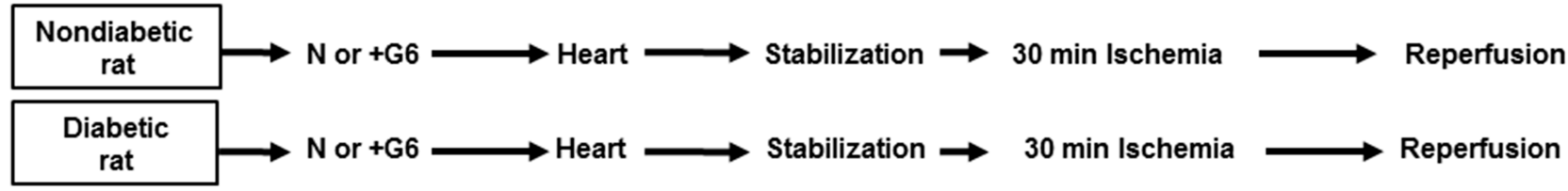

\section{Experiment 3}

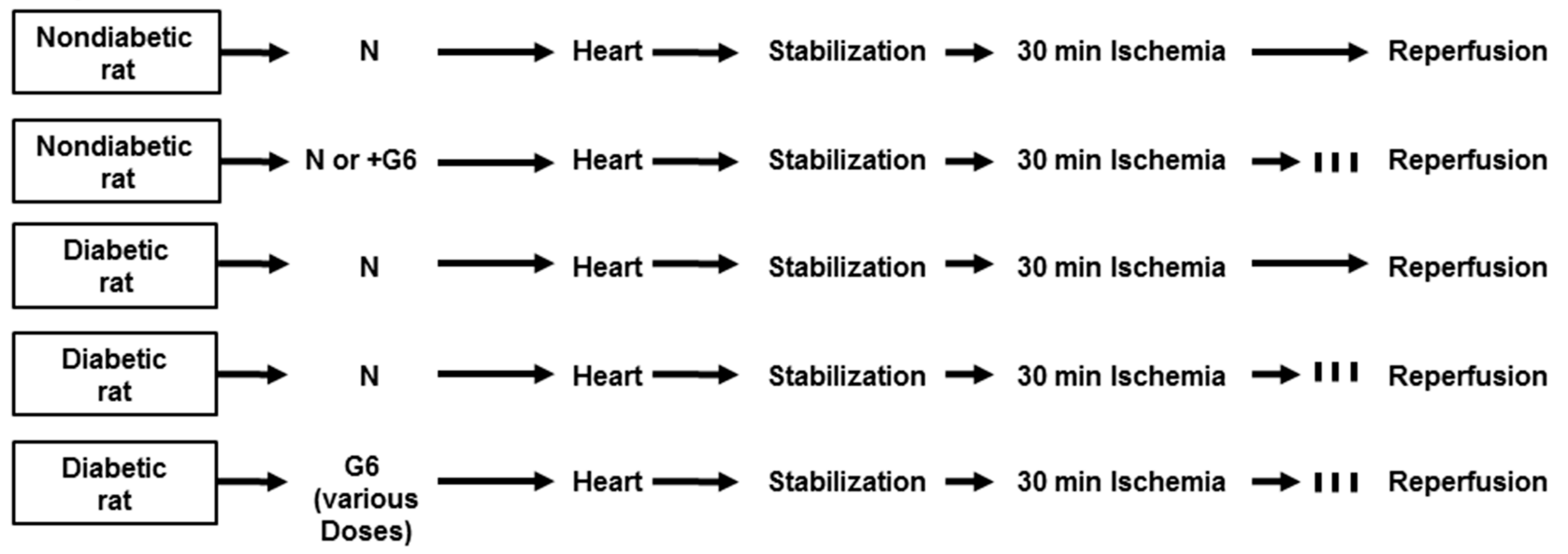

\section{I 30 seconds LV Pacing}

Figure I Schematic representation showing the experimental protocols used for the study ( $\mathrm{n}=6$ per group). Experiment I shows a dose-dependent effect of G6 PAMAM on the heart. Experiment 2 shows normal and diabetic rats treated with G6 PAMAM $40 \mathrm{mg} / \mathrm{kg}$ for 4 weeks or with normal saline. Experiment 3 shows nondiabetic rats treated with normal saline and diabetic rats treated with variable doses of G6 PAMAM (10, 20 or $40 \mathrm{mg} / \mathrm{kg}$ ).

Abbreviations: N, normal saline; G6, G6 PAMAM.

All hearts isolated from non-diabetic and diabetic rats were subjected to $30 \mathrm{~min}$ of ischemia produced by LAD coronary artery occlusion. The LAD coronary artery was encircled by a snare approximately $0.5 \mathrm{~cm}$ below the atrioventricular groove and a small rigid plastic tube was positioned between the heart and the snare to ensure complete occlusion of coronary artery. PPC involved three alternate RA and LV pacing episodes $30 \mathrm{sec}$ each. The on and off cycles of pacing were selected based on our previous study. ${ }^{43}$ In paced animals, a pacing electrode was fixed to the posterior basal LV wall and connected to a pacemaker set to the required pacing frequency. Simultaneous atrioventricular (AV) pacing (AV-interval $=0 \mathrm{~ms}$ ) was used for ventricular pacing to ensure complete ventricular activation initiated from the pacing electrode.

\section{Data Collection and Processing}

LV function was evaluated by the assessment of LV hemodynamics; LV end diastolic pressure (LVEDP), LV developed pressure (DPmax) and LV contractility $(+\mathrm{dP} / \mathrm{dt}$ or $-\mathrm{dP} / \mathrm{dt}$ ). Coronary-vascular dynamics were evaluated by the assessment of the coronary flow (CF) and coronary-vascular resistance (CVR). Cardiac functions were measured as previously described. ${ }^{41}$ Briefly, a water-filled latex balloon was placed and secured in the LV cavity. The balloon was attached to a pressure transducer and a "DC-Bridge amplifier (DC-BA)" with a pressure module (DC-BA type 660, Hugo Sachs Electronik, Germany) interfaced to a personal computer for on-line monitoring of DPmax. LV developed pressure was derived from online acquisition of LVESP using Max-Min module (Number MMM type 668, Hugo Sachs ElektronikHarvard ApparatusGmbH, Germany) which has the ability to 
convert the output from DC bridge amplifier to DPmax by subtracting LVEDP from the LVESP.

Coronary flow was continuously measured using an electromagnetic flow probe attached to the inflow of the aortic cannula and interfaced to a personal computer. Continuous monitoring of the $\mathrm{CF}$ in $\mathrm{mL} / \mathrm{min}$ was done digitally and verified manually by timed collection of coronary effluent. The CVR was computed for every 10 seconds along with the hemodynamics data by an online data acquisition program (Isoheart software V 1.524-S, Hugo Sachs Electronik, Germany).

\section{Sample and Tissue Collection and Storage} Coronary effluent was collected at the end of reperfusion phase. The hearts were also collected at the end of reperfusion. All coronary effluents were frozen in liquid nitrogen and stored at $-80^{\circ} \mathrm{C}$ for the assessment of the creatine kinase and lactate dehydrogenase levels.

\section{Cardiac Damage Assessment via Creatine Kinase and Lactate Dehydrogenase Levels}

Cardiomyocytes injury was evaluated by measuring creatine kinase $(\mathrm{CK})$ and lactate dehydrogenase $(\mathrm{LDH})$ release in the coronary effluent during the reperfusion period as described previously by Ferrera et al. ${ }^{44}$

\section{Statistical Analysis}

The data were represented as mean \pm SEM. Two-way analysis of variance (ANOVA) was used to assess the statistical differences between the means of different groups. If an analysis of variance showed a significant difference, post hoc analysis with Tukey's test was used for further comparison. An unpaired two-sided $t$-test was used to analyze differences in the heart enzyme levels between the groups. In all cases, $\mathrm{p}<0.05$ was considered statistically significant.

\section{Results}

The Dose-Dependent Effects of ex vivo Direct Administration of G6 PAMAM on Recovery of Cardiac Function in Isolated Hearts Following I/R Injury

To examine the effect of acute, ex vivo direct administration of G6 PAMAM dendrimer on isolated healthy nondiabetic hearts, G6 PAMAM dendrimer was infused to the heart in the reperfusion buffer at various concentrations $(0.1,1.0$ and $2.0 \mu \mathrm{g} / \mathrm{mL}$, respectively). LV dynamics (DPmax and LVEDP), coronaryvascular dynamics (CF and CVR) and LV contractility $(+\mathrm{dP} / \mathrm{dt}$ and -dP/dt) were not significantly different between the groups during baseline heart perfusion. Hearts exposed to ischemia showed a considerable deterioration in LV dynamics, coronary-vascular dynamics and LV contractility (Figure 2). Acute, ex vivo direct administration of G6 PAMAM dendrimer to healthy control hearts resulted in a dose-dependent deterioration in the LV dynamics, coronary-vascular dynamics, LV contractility and increased CK and LDH levels compared to control (Figure 2, Tables 1 and 2). For example, at the highest dose G6 PAMAM dendrimer significantly reduced Dpmax and $\mathrm{CF}$ to about $10 \%$ of control $(\mathrm{P}<0.05)$ and significantly exacerbated LVEDP and CVR by 2.5 to 5 folds, respectively $(\mathrm{P}<0.05$; Figure 2). The $\mathrm{CF}$ was reduced to about $10 \%$ of the control and the CVR was increased by about 5 folds $(\mathrm{P}<0.05$; Figure 2$)$. Cardiac enzyme levels of CK and LDH were non-significantly increased with increasing doses of G6 PAMAM relative to controls (Table 2).

\section{The Effect of Chronic, Repeated in vivo Administration of $\mathrm{G} 6$ PAMAM on Recovery of Cardiac Function Following I/R Injury in Normal and Diabetic Hearts}

We next investigated whether chronic in vivo administration of G6 PAMAM dendrimer impaired recovery of cardiac function in healthy and diabetic hearts following $\mathrm{I} / \mathrm{R}$ injury. Chronic, repeated daily i.p. administration of G6 PAMAM dendrimer $(40 \mathrm{mg} / \mathrm{kg}$ ) for 4 weeks in healthy, nondiabetic hearts resulted in a significant deterioration in LV hemodynamics, coronary-vascular dynamics, LV contractility and increased heart enzyme levels compared to controls ( $\mathrm{P}<0.05$; Figure 3 and Tables 1 and 2). For example, G6 PAMAM dendrimer treatment significantly reduced DPmax by about $60 \%$ and CF by about $50 \%$ compared to ischemia alone ( $\mathrm{P}<0.05$; Figure 3$)$. Although G6 PAMAM significantly exacerbated recovery in CVR by about $30 \%$ $(\mathrm{P}<0.05)$, it did not appear to significantly affect LVEDP relative to ischemia alone (Figure 3).

In diabetic hearts, recovery of cardiac function following I/ $\mathrm{R}$ injury was significantly impaired compared to healthy (nondiabetic) hearts (Figure 3). For example, I/R injury in diabetic hearts reduced DPmax and CF to about $10-15 \%$ of baseline whereas marked (2-3 folds) increase in LVEDP and CVR were observed in these hearts $(\mathrm{P}>0.05$; Figure 3$)$. Although there was a general trend towards a further, albeit modest, impairment in recovery of cardiac function (DPmax, LVEDP, and 

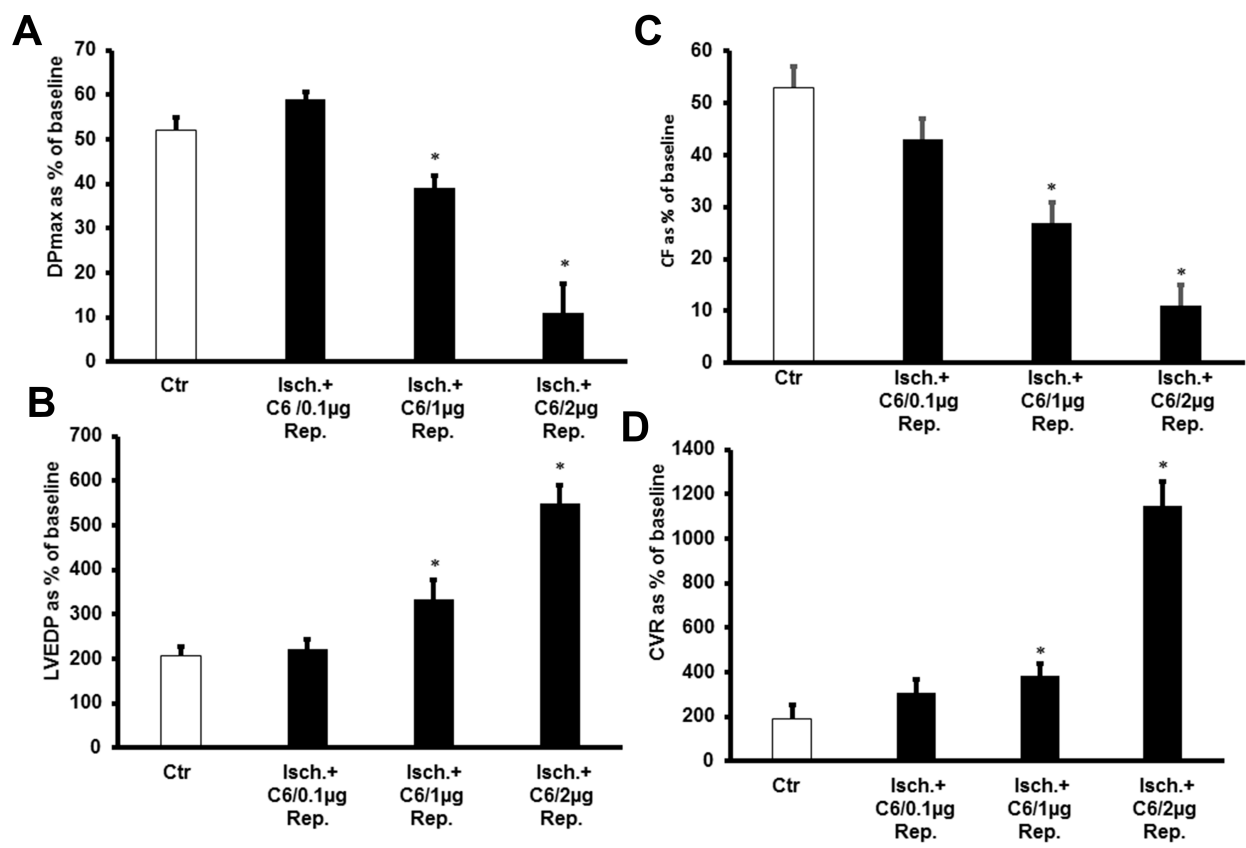

Figure 2 The dose-dependent effects of ex vivo direct administration of G6 PAMAM (0.I, I.0 and $2 \mu g / \mathrm{mL})$ on recovery of cardiac function in isolated non-diabetic hearts following I/R injury $(n=6)$. Recovery of the heart functions: (A) DPmax; (B) LVEDP; (C) CF; and (D) CVR. The data were computed at 30 min of reperfusion and are expressed as the means $\pm \mathrm{SEM}$. $* \mathrm{P}<0.01$ compared to the respective control.

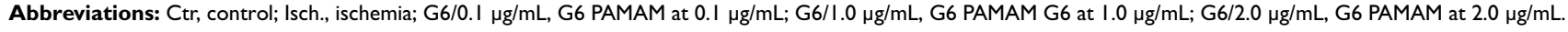

$\mathrm{CF}$ ) in diabetic animals receiving repeated i.p. treatment with G6 PAMAM dendrimer, this was only statistically significant for $\mathrm{CF}(\mathrm{P}<0.05$; Figure 3, Tables 1 and 2). G6 PAMAM treatment had no statistically significant effect on CVR of diabetic hearts ( $\mathrm{P}>0.05$; Figure 3, Tables 1 and 2). Cardiac enzyme $\mathrm{CK}$ and $\mathrm{LDH}$ levels were not significantly altered by PAMAM treatment relative to ischemia alone controls (Table 2).

\section{The Impact of in vivo Administration of G6 PAMAM on PPC-Mediated Recovery of Cardiac Function Following I/R Injury in Normal and Diabetic Hearts}

We next investigated the impact of G6 PAMAM dendrimer treatment on functional recovery of normal and diabetic hearts following PPC. In healthy control hearts, PPC significantly improved recovery of hearts following I/R injury (Figure 4 and Table 1). This improvement of heart function was accompanied by a significant reduction in the $\mathrm{CK}$ and LDH levels $(\mathrm{P}<0.001)$ compared to the untreated controls (Table 2). However, these protective effects of PPC were significantly attenuated in hearts isolated from non-diabetic control rats receiving chronic in vivo daily i.p injections of G6 PAMAM dendrimer (40 mg/kg) for 4 weeks (Figure 4, Tables 1 and 2). For example, the 50\% improvement in
LVEDP observed with PPC was completely abrogated by in vivo G6 PAMAM dendrimer treatment in control, nondiabetic (healthy) rats (Figure 4, Tables 1 and 2).

We next examined the effects of PPC in isolated diabetic hearts and whether in vivo administration of G6 PAMAM dendrimer altered PPC-mediated changes in cardiac function in isolated hearts from diabetic rats receiving daily i.p. doses of 10,20 or $40 \mathrm{mg} / \mathrm{kg}$ of G6 PAMAM dendrimer for 4 weeks (Figure 5, Tables 1 and 2). In contrast to healthy hearts, PPC did not significantly improve cardiac function or cardiac enzyme levels in diabetic hearts subjected to $\mathrm{I} / \mathrm{R}$ injury. Furthermore, increasing doses of G6 PAMAM dendrimer did not significantly alter cardiac function in diabetic hearts compared to that observed with PPC alone in hearts isolated from diabetic animals ( $p>0.05$; Figure 5, Tables 1 and 2).

\section{Discussion}

PAMAM dendrimer nanoparticles are gaining increasing attention for their potential clinical applications as nanomedicines for drug delivery. However, their full nanotoxicological profiling in vivo especially their effects on the mammalian heart function are not completely understood. In this study, we have investigated the ex vivo and in vivo effects of a G6 PAMAM dendrimer on 
Table I Effects of Ischemia Reperfusion, G6 PAMAM and PPC on Left Ventricle Contractility

\begin{tabular}{|c|c|c|c|c|}
\hline Treatment & $+d P / d t$ & $P$ value & $-d P / d t$ & $P$ value \\
\hline Ctr & $60.08 \pm 6.27$ & - & $45.93 \pm 3.78$ & - \\
\hline Isch. + PPC & $84.72 \pm 4.34$ & 0.04 & $62.89 \pm 1.92 *$ & 0.02 \\
\hline Isch. + G6/40mg & $53.42 \pm 1.93$ & 0.261 & $51.32 \pm 1.38$ & 0.213 \\
\hline Isch. + G6/40mg + PPC & $52.56 \pm 0.87$ & 0.660 & $56.19 \pm 1.34$ & 0.127 \\
\hline Ctr & $62.16 \pm 5.17$ & - & $53.72 \pm 4.62$ & - \\
\hline Diabetic + Isch. + PPC & $48.15 \pm 1.32$ & 0.395 & $54.42 \pm 1.51$ & 0.198 \\
\hline Diabetic + G6/10mg + Isch. + PPC & $57.62 \pm 3.56$ & 0.959 & $58.94 \pm 3.79$ & 0.076 \\
\hline Diabetic + G6/20mg + Isch. + PPC & $54.45 \pm 1.95$ & 0.798 & $54.79 \pm 3.66$ & 0.202 \\
\hline Diabetic + G6/40mg + Isch. + PPC & $59.37 \pm 1.91$ & 0.824 & $57.53 \pm 1.80$ & 0.093 \\
\hline Ctr & $52.20 \pm 1.98$ & 0.412 & $49.10 \pm 1.11$ & 0.321 \\
\hline Ctr + Isch. + G6/0.1 $\mu \mathrm{g}$ & $49.40 \pm 3.67$ & 0.734 & $42.40 \pm 3.82$ & 0.162 \\
\hline Ctr + Isch. G6/I.0ug & $31.31 \pm 1.13^{*}$ & 0.01 & $23.12 \pm 1.22 *$ & 0.01 \\
\hline $\mathrm{Ctr}+$ Isch. + G6/2.0 $\mu \mathrm{g}$ & $07.37 \pm 3.34 * *$ & 0.001 & $09.13 \pm 1.13 * *$ & 0.001 \\
\hline
\end{tabular}

Note: $* \mathrm{P}<0.01$ and $* * \mathrm{P}<0.00 \mathrm{I}$ compared to the respective control.

Abbreviations: Ctr, control; Isch, ischemia; PPC, pacing postconditioning; G6/10 mg, G6 PAMAM at 10 mg/kg; G6/20mg, G6 PAMAM at 20 mg/kg; G6/40 mg, G6 PAMAM at $40 \mathrm{mg} / \mathrm{kg}$; G6/0.I $\mu \mathrm{g}$, G6 PAMAM at $0.1 \mu \mathrm{g} / \mathrm{mL} ; \mathrm{G} 6 / 1.0 \mu \mathrm{g}$, G6 PAMAM at I.0 $\mu \mathrm{g} / \mathrm{mL} ; \mathrm{G} 6 / 2.0 \mu \mathrm{g}$, G6 PAMAM at $2.0 \mu \mathrm{g} / \mathrm{mL}$.

Table 2 Effects of Ischemia Reperfusion, G6 PAMAM and PPC on Cardiac Enzymes Levels

\begin{tabular}{|c|c|c|c|c|}
\hline Treatment & $\begin{array}{l}\text { CK } \\
\text { IU/L }\end{array}$ & P value & $\begin{array}{l}\text { LDH } \\
\text { IU/L }\end{array}$ & $P$ value \\
\hline Ctr & $9.42 \pm 1.74$ & - & $8.83 \pm 1.05$ & - \\
\hline Isch. + PPC & $3.12 \pm 1.23^{*}$ & 0.01 & $3.64 \pm 1.43 *$ & 0.01 \\
\hline Isch. + G6/40mg & $10.11 \pm 1.24$ & 0.512 & $9.23 \pm 1.84$ & 0.553 \\
\hline Isch. + G6/40mg + PPC & $8.95 \pm 1.04$ & 0.344 & $7.38 \pm 1.90$ & 0.541 \\
\hline Ctr & $9.63 \pm 2.24$ & - & $8.92 \pm 1.85$ & - \\
\hline Diabetic + Isch. + PPC & $11.13 \pm 2.12$ & 0.316 & $9.61 \pm 2.11$ & 0.342 \\
\hline Diabetic + G6/10mg +Isch. + PPC & $9.7 I \pm 1.83$ & 0.271 & $10.37 \pm 2.28$ & 0.371 \\
\hline Diabetic + G6/20mg + Isch. + PPC & $8.93 \pm 1.95$ & 0.253 & $9.57 \pm 1.17$ & 0.406 \\
\hline Diabetic + G6/40mg + Isch. + PPC & $10.71 \pm 1.79$ & 0.283 & $9.87 \pm 1.62$ & 0.342 \\
\hline Ctr & $9.20 \pm 1.68$ & 0.312 & $9.17 \pm 2.34$ & 0.321 \\
\hline Ctr + Isch. + G6/0.I $\mu \mathrm{g}$ & $9.40 \pm 2.57$ & 0.437 & $9.46 \pm 2.61$ & 0.564 \\
\hline 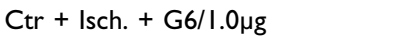 & $10.31 \pm 2.13$ & 0.412 & $|1.32 \pm| .5 \mid$ & 0.426 \\
\hline $\mathrm{Ctr}+$ Isch. $+\mathrm{G} 6 / 2.0 \mu \mathrm{g}$ & $11.37 \pm 2.34$ & 0.354 & $11.12 \pm 1.34$ & 0.321 \\
\hline
\end{tabular}

Note: $* \mathrm{P}<0.01$ compared to the respective control.

Abbreviations: Ctr, control; Isch, ischemia; PPC, pacing postconditioning; G6/10 mg, G6 PAMAM dendrimer at $10 \mathrm{mg} / \mathrm{kg}$; G6/20 mg, G6 PAMAM at $20 \mathrm{mg} / \mathrm{kg}$; G6/40 mg, G6 PAMAM at $40 \mathrm{mg} / \mathrm{kg} ; \mathrm{G} 6 / 0.1 \mu \mathrm{g}$, G6 PAMAM dendrimer at $0.1 \mu \mathrm{g} / \mathrm{mL} ; \mathrm{G} 6 / 1.0 \mu \mathrm{g}, \mathrm{G} 6$ PAMAM at $1.0 \mu \mathrm{g} / \mathrm{mL} ; \mathrm{G} 6 / 2.0 \mu \mathrm{g}, \mathrm{G} 6 \mathrm{PAMAM}$ at $2.0 \mu \mathrm{g} / \mathrm{mL}$.

several cardiac function parameters in control (healthy non-diabetic) and diabetic rat hearts following $\mathrm{I} / \mathrm{R}$ injury.

The major findings of this study are that ex vivo and in vivo administration of G6 PAMAM dendrimer nanoparticles attenuated recovery of cardiac function in control (healthy) hearts subjected to I/R injury. Furthermore, chronic in vivo repeat administration of G6 PAMAM at a dose of $40 \mathrm{mg} / \mathrm{kg}$ daily for 4 weeks completely negated the beneficial effects of PPC on cardiac recovery from $I / R$ injury in these hearts. In diabetic hearts, G6 PAMAM dendrimer treatment only significantly exacerbated recovery of CF whereas other cardiac parameters (DPmax, LVEDP and CVR) were not significantly affected - implying possible differential effects in diabetes versus healthy hearts. Our findings are therefore extremely important in the toxicological evaluation of PAMAM dendrimers for potential clinical applications in physiological and pathological settings.

We have been studying the toxicological profile of drug delivery systems including PAMAM dendrimers from 

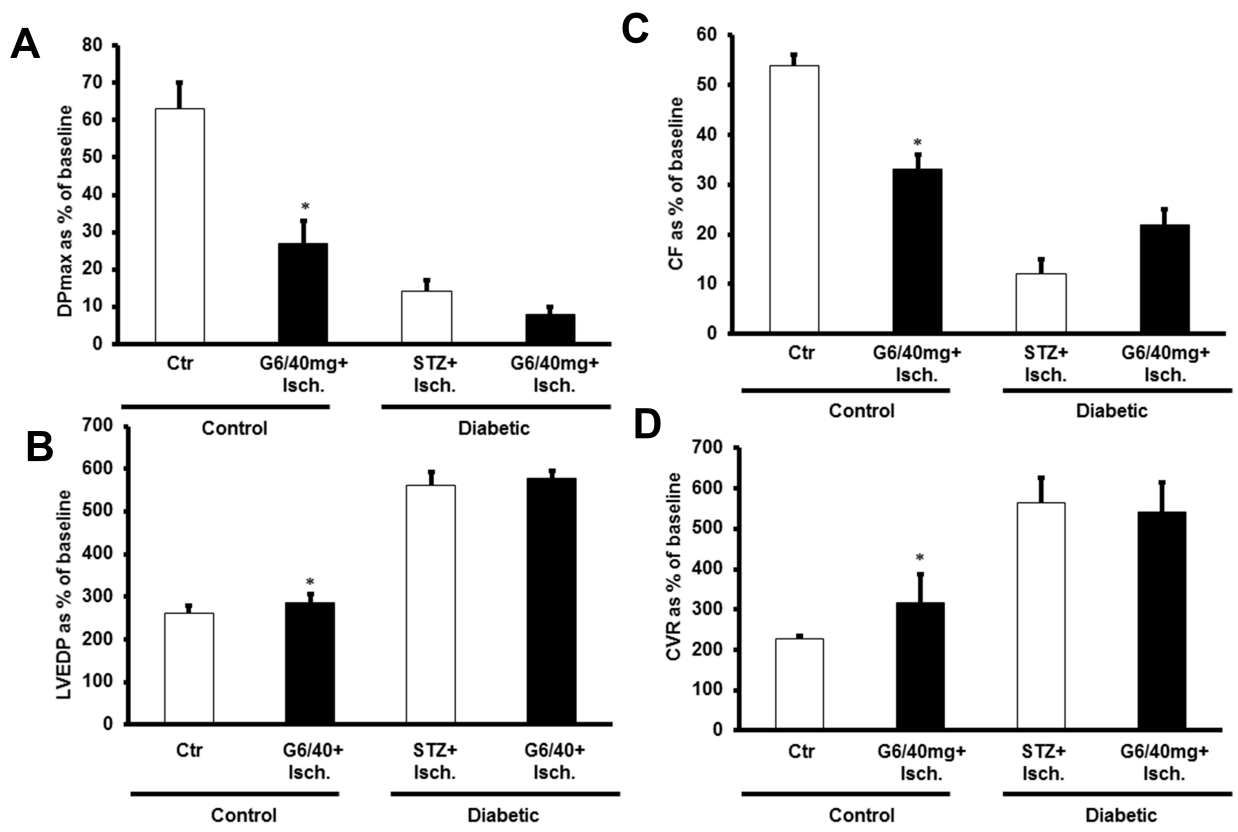

Figure 3 The effect of chronic, repeated in vivo administration of G6 PAMAM on recovery of cardiac function following $1 / R$ injury in normal and diabetic hearts ( $\mathrm{n}=6$ ). Recovery of the heart functions: (A) DPmax; (B) LVEDP; (C) CF; and (D) CVR. The data were computed at 30 min of reperfusion and are expressed as the means \pm SEM. $* \mathrm{P}<0.0$ l compared to the respective control.

Abbreviations: Ctr, control; Isch, ischemia; PPC, pacing postconditioning, G6/40mg, G6 PAMAM at $40 \mathrm{mg} / \mathrm{kg}$.
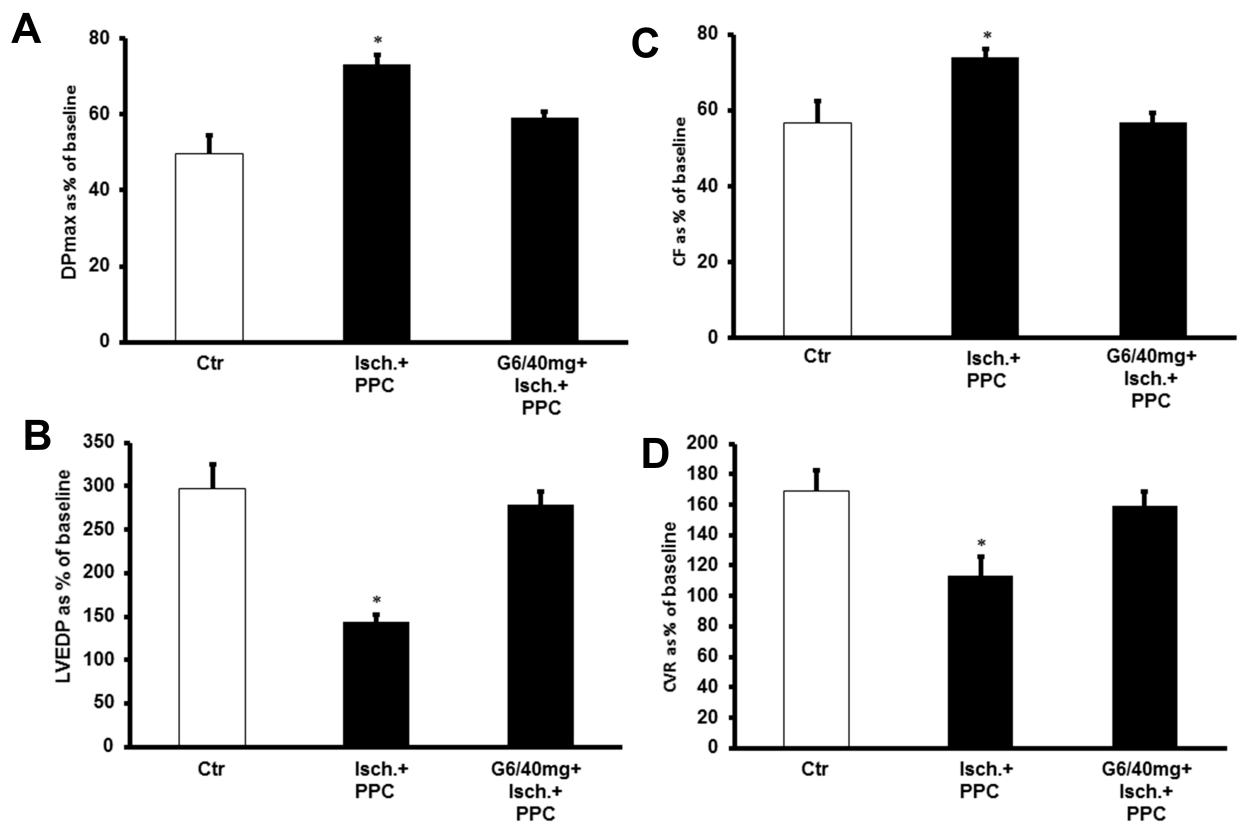

Figure 4 PPC-mediated cardiac protection in nondiabetic hearts and the effect of in vivo administration of G6 PAMAM dendrimer ( $\mathrm{n}=6$ ). Post-ischemic recovery of the heart function: (A) DPmax; (B) LVEDP; (C) CF; and (D) CVR. The data were computed at 30 min of reperfusion and are expressed as the means \pm SEM. $* P<0.01$ compared to the respective control.

Abbreviations: Ctr, control; Isch, ischemia; PPC, pacing postconditioning; G6/40, G6 PAMAM at $40 \mathrm{mg} / \mathrm{kg}$.

their toxicogenomic to proteomic effects in vitro and in vivo. ${ }^{7-11,45-50}$ These studies have highlighted that beyond their drug delivery role, PAMAMs are actually biologically active polymers that have the potential to affect important genes and cell signaling protein networks in vitro and in vivo. Our findings from the present study 

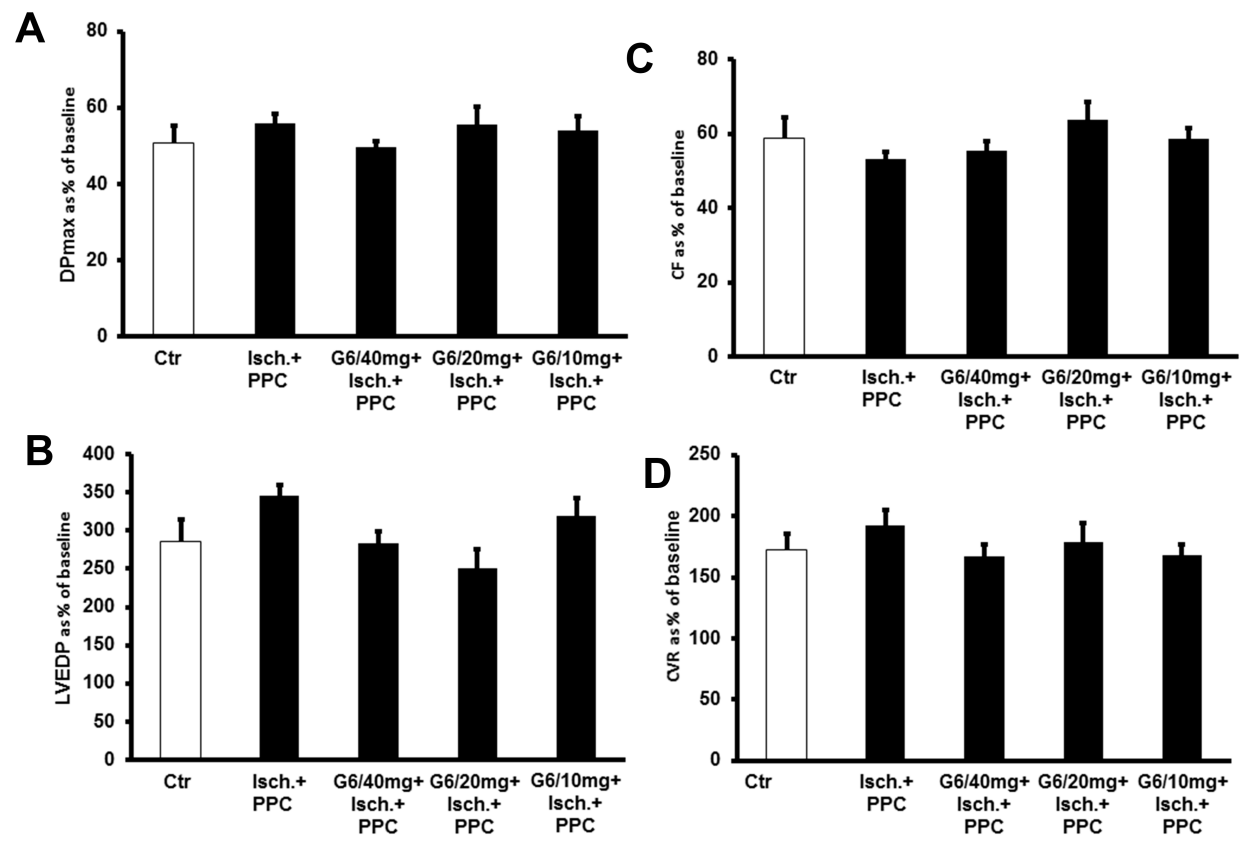

Figure 5 PPC-mediated protection in diabetic hearts and the effect of 4 weeks in vivo treatment with different doses of G6 PAMAM dendrimer (I0, 20 and 40 mg/kg) ( $\mathrm{n}=6$ ). Post-ischemic recovery of the heart functions: (A) DPmax; (B) LVEDP; (C) CF; and (D) CVR. The data were computed at 30 min of reperfusion and are expressed as the means \pm SEM.

Abbreviations: Ctr, control; Isch, ischemia; PPC, pacing postconditioning; G6/l0, G6 PAMAM at 10 mg/kg; G6/20, G6 PAMAM at 20 mg/kg; G6/40, G6 PAMAM at 40 mg/kg.

support this notion and show for the first time that G6 PAMAM dendrimer nanoparticles can dose-dependently compromise cardiac function recovery following $\mathrm{I} / \mathrm{R}$ injury (such as would be the case after a "heart attack" or myocardial infarction). Although not studied here, the likely mechanisms for the acute, direct effects of G6 PAMAM dendrimer following ex vivo administration in the isolated heart might involve either: 1) rapid inhibition of key survival/cardiac function recovery pathways or 2) PAMAM nanoparticle-induced clot formation and induction of coronary-vascular occlusion, or 3) a combination of these two mechanisms. Direct rapid intravenous administration of cationic PAMAM nanoparticles into the bloodstream is known to induce hemolysis and blood coagulation, ${ }^{51}$ though this is thought to be less likely following i.p. administration of these dendrimers. ${ }^{10,12}$ The fact that in this study, even chronic i.p administration G6 PAMAM dendrimer attenuated cardiac function recovery from $\mathrm{I} / \mathrm{R}$ injury coupled with our previous finding that i.p administration of G6 PAMAM dendrimer actually improved vascular function in vivo, implies that it is more likely that this dendrimer inhibits key cardiac survival/recovery signaling pathways essential for hearts to recover from $\mathrm{I} / \mathrm{R}$ injury. In this regard, we have previously shown that signaling pathways involving the epidermal growth factor receptor are essential for hearts to recover from I/R injury. ${ }^{52}$ Furthermore, the fact that PAMAM dendrimers can also inhibit EGFR signaling in vitro and in vivo ${ }^{8-11}$ leads us to speculate that G6 PAMAM dendrimer most likely impairs cardiac recovery in vitro and in vivo via inhibition of this key EGFR-dependent salvage pathway necessary for the recovery of hearts from $I / R$ injury.

Similarly, the fact that G6 PAMAM dendrimer negated the beneficial effects of PPC in healthy hearts also suggests that this dendrimer could likely interfere with these beneficial signaling pathways induced by PPC. Indeed, there appears to be significant identity and overlap in the nature of the recovery pathways induced by PPC, preconditioning (PC) and postconditioning (PostC). ${ }^{43,53,54}$ It is quite likely that the EGFR pathway is involved in PPCinduced improvements in cardiac function, as we have previously shown the EGFR signaling is critical for mediating the beneficial effects of ischemic PC. ${ }^{55}$ Thus, our proposed mechanism of G6 PAMAM-mediated inhibition of EGFR leading to impaired recovery of cardiac function following I/R injury could also account for the dendrimers ability to completely negate the beneficial effects of PPC seen in the present study. 
It is noteworthy that in the diabetic pathological state, in vivo administration of G6 PAMAM dendrimer did not significantly exacerbate recovery of cardiac function (with the exception of CF) beyond ischemia alone. The most likely explanation for this phenomenon is that $\mathrm{I} / \mathrm{R}$ injury in diabetic hearts leads to a near maximal impairment in cardiac function from which little recovery is possible, and thus in vivo administration of G6 PAMAM dendrimer cannot have any additional detrimental effects on cardiac function as the damage threshold from which hearts can recover following $\mathrm{I} / \mathrm{R}$ has already been exceeded in this pathological state. Indeed, we reported similar findings with conventional small molecule inhibitors of EGFR in diabetic rats. ${ }^{52}$ Furthermore, this assertion may also account for the inability of PPC to enhance cardiac function recovery in diabetic rats that was in contrast to control nondiabetic hearts- a fact we have also noted previously. ${ }^{56,57}$ These findings suggest there is a cardiac damage thresh-hold beyond which PPC is ineffective and that might also explain why G6 PAMAM dendrimer was unable to exacerbate recovery even further as near maximal damage was already in existence in the diabetic heart pathology. Indeed, it is well known that salvage signaling mechanisms of postconditioning are impaired in diabetes mellitus. ${ }^{47,58,59}$ In addition to the above explanations, a cationic G4 PAMAM dendrimer was found to inhibit heart mitochondrial function when administered in vivo by daily i.p injections at a dose of $0.5 \mathrm{mmol} / \mathrm{kg}$ for 60 days ${ }^{60}$ implying that PAMAMs may also impair cardiac function through compromised cardiac mitochondrial function and bioenergetics. Thus, if PAMAM drug delivery vehicles were to be used systemically for potential longterm therapies as is envisaged for patients for chronic diseases, then our 4-week treatment study suggests that cardiac recovery may be compromised in such patients already receiving chronic PAMAMs who might subsequently undergo a heart attack (MI) or develop other cardiac pathologies. However, in another study using cationic G3 PAMAM dendrimer, the effects of PAMAM on heart mitochondria function could not be confirmed due to lethal toxicity of the G3 PAMAM dendrimer when administered at a dose of $20 \mathrm{mg} / \mathrm{kg} /$ day for 60 days. ${ }^{61}$

In contrast to naked PAMAMs, drugs conjugated on the surface of PAMAMs can be engineered to afford cardioprotection. For example, a G4 PAMAM dendrimer conjugated with 64 moieties of an agonist of A3 adenosine receptor (AR) mediated cardioprotective effects without inducing detrimental hemodynamic side effects in an isolated mouse heart model of $\mathrm{I} / \mathrm{R}$ injury. ${ }^{62}$ Other polymer nanoparticles bearing antioxidants and/or antiinflammatory drugs such as curcumin or resveratrol have also been shown to be cardioprotective. ${ }^{63-65}$ Therefore, it seems that if suitably modified, PAMAM dendrimers can be converted from potentially cardiotoxic to cardioprotective agents. Indeed, several strategies now exist to minimize the toxicity of cationic polymers that including reducing the number of surface cationic charges, altering the surface chemistry to neutral or anionic or by conjugating with other drugs or polymers such as polyethylene glycol. ${ }^{63,64}$ Based on our findings with naked G6 PAMAM dendrimer, such modifications may be essential for PAMAM dendrimers to meet the required safety profile for progression into the clinic as potential nanomedicines.

\section{Conclusions}

In this study, we have shown for the first time that acute ex vivo or chronic in vivo treatment with naked G6 PAMAM dendrimer can significantly compromise recovery of non-diabetic hearts from $\mathrm{I} / \mathrm{R}$ injury and can further negate the beneficial effects of PPC. Surprisingly, G6 PAMAM dendrimer generally did not significantly affect cardiac function of diabetic hearts implying its differential effects in pathological states. Although further mechanistic studies (a potential limitation of this study) are needed, our findings are extremely important in the toxicological evaluation of PAMAM dendrimers for potential clinical applications in physiological and pathological settings. Further studies are needed in order to demonstrate if despite the undesired effect of "naked" PAMAM on experimental cardiac ischemia, PAMAMs bearing therapeutic molecules could impart important beneficial effects in functional recovery of ischemic heart diseases.

\section{Acknowledgments}

The research in the laboratory of Professor Saghir Akhtar was funded by Qatar University grant QUCG-CMED $-19 / 20-3$ and the research laboratory of Dr. Fawzi Babiker was funded by Kuwait University.

\section{Disclosure}

The authors report no conflicts of interest in this work. 


\section{References}

1. Abedi-Gaballu F, Dehghan G, Ghaffari M, et al. PAMAM dendrimers as efficient drug and gene delivery nanosystems for cancer therapy. Appl Mater Today. 2018;12:177-190. doi:10.1016/j.apmt.2018.05.002

2. Kannan RM, Nance E, Kannan S, Tomalia DA. Emerging concepts in dendrimer-based nanomedicine: from design principles to clinical applications. J Intern Med. 2014;276(6):579-617. doi:10.1111/ joim. 12280

3. Li J, Liang H, Liu J, Wang Z. Poly (amidoamine) (PAMAM) dendrimer mediated delivery of drug and pDNA/siRNA for cancer therapy. Int $J$ Pharm. 2018;546(1-2):215-225. doi:10.1016/j. ijpharm.2018.05.045

4. Tomalia DA, Reyna LA, Svenson S. Dendrimers as multi-purpose nanodevices for oncology drug delivery and diagnostic imaging. Biochem Soc Trans. 2007;35(Pt 1):61-67. doi:10.1042/BST0350061

5. Luo K, He B, Wu Y, Shen Y, Gu Z. Functional and biodegradable dendritic macromolecules with controlled architectures as nontoxic and efficient nanoscale gene vectors. Biotechnol Adv. 2014;32 (4):818-830. doi:10.1016/j.biotechadv.2013.12.008

6. Sadekar S, Ghandehari H. Transepithelial transport and toxicity of PAMAM dendrimers: implications for oral drug delivery. Adv Drug Deliv Rev. 2012;64(6):571-588. doi:10.1016/j.addr.2011.09.010

7. Akhtar S, Al-Zaid B, El-Hashim AZ, Chandrasekhar B, Attur S, Benter IF. Impact of PAMAM delivery systems on signal transduction pathways in vivo: modulation of ERK $1 / 2$ and p38 MAP kinase signaling in the normal and diabetic kidney. Int J Pharm. 2016;514 (2):353-363. doi:10.1016/j.ijpharm.2016.03.039

8. Akhtar S, Chandrasekhar B, Attur S, Dhaunsi GS, Yousif MH, Benter IF. Transactivation of ErbB family of receptor tyrosine kinases is inhibited by angiotensin-(1-7) via its mas receptor. PLoS One. 2015;10(11):e0141657. doi:10.1371/journal.pone.0141657

9. Akhtar S, Chandrasekhar B, Attur S, Yousif MH, Benter IF. On the nanotoxicity of PAMAM dendrimers: Superfect ${ }^{\circledR}$ stimulates the EGFR-ERK1/2 signal transduction pathway via an oxidative stressdependent mechanism in HEK 293 cells. Int J Pharm. 2013;448 (1):239-246. doi:10.1016/j.ijpharm.2013.03.039

10. Akhtar S, Chandrasekhar B, Yousif MH, Renno W, Benter IF, ElHashim AZ. Chronic administration of nano-sized PAMAM dendrimers in vivo inhibits EGFR-ERK1/2-ROCK signaling pathway and attenuates diabetes-induced vascular remodeling and dysfunction. Nanomedicine. 2019;18:78-89. doi:10.1016/j.nano.2019.02.012

11. Akhtar S, El-Hashim AZ, Chandrasekhar B, Attur S, Benter IF. Naked polyamidoamine polymers intrinsically inhibit angiotensin II-mediated EGFR and ErbB2 transactivation in a dendrimer generation- and surface chemistry-dependent manner. Mol Pharm. 2016;13(5):1575-1586. doi:10.1021/acs.molpharmaceut.6b00045

12. Chauhan AS, Diwan PV, Jain NK, Tomalia DA. Unexpected in vivo anti-inflammatory activity observed for simple, surface functionalized poly(amidoamine) dendrimers. Biomacromolecules. 2009;10 (5):1195-1202. doi:10.1021/bm9000298

13. White HD, Chew DP. Acute myocardial infarction. Lancet. 2008;372 (9638):570-584. doi:10.1016/S0140-6736(08)61237-4

14. Libby P. Current concepts of the pathogenesis of the acute coronary syndromes. Circulation. 2001;104(3):365-372. doi:10.1161/01. CIR.104.3.365

15. Soler EP, Ruiz VC. Epidemiology and risk factors of cerebral ischemia and ischemic heart diseases: similarities and differences. Curr Cardiol Rev. 2010;6(3):138-149. doi:10.2174/15734031079 1658785

16. Ma XJ, Yin HJ, Chen KJ. Appraisal of the prognosis in patients with acute myocardial infarction treated with primary percutaneous coronary intervention. Chin J Integr Med. 2009;15(3):236-240. doi:10.1007/s11655-009-0236-3
17. Tanaka A, Kawarabayashi T, Nishibori Y, et al. No-reflow phenomenon and lesion morphology in patients with acute myocardial infarction. Circulation. 2002;105(18):2148-2152. doi:10.1161/01. CIR.0000015697.59592.07

18. Murry CE, Jennings RB, Reimer KA. Preconditioning with ischemia: a delay of lethal cell injury in ischemic myocardium. Circulation. 1986;74(5):1124-1136. doi:10.1161/01.CIR.74.5.1124

19. Zhao ZQ, Corvera JS, Halkos ME, et al. Inhibition of myocardial injury by ischemic postconditioning during reperfusion: comparison with ischemic preconditioning. Am J Physiol Heart Circ Physiol. 2003;285(2):H579-588. doi:10.1152/ajpheart.01064.2002

20. Tsang A, Hausenloy DJ, Mocanu MM, Yellon DM. Postconditioning: a form of "modified reperfusion" protects the myocardium by activating the phosphatidylinositol 3-kinase-Akt pathway. Circ Res. 2004;95(3):230-232. doi:10.1161/01.RES.0000138303.76488.fe

21. Ferdinandy P, Schulz R, Baxter GF. Interaction of cardiovascular risk factors with myocardial ischemia/reperfusion injury, preconditioning, and postconditioning. Pharmacol Rev. 2007;59(4):418-458. doi:10. 1124/pr.107.06002

22. Babiker FA, Joseph S, Juggi JS. What's new in salvage of the ischemic myocardium: estrogen postconditioning. Med Princ Pract. 2011;20(6):495-496. doi:10.1159/000330036

23. Kin H, Zhao ZQ, Sun HY, et al. Postconditioning attenuates myocardial ischemia-reperfusion injury by inhibiting events in the early minutes of reperfusion. Cardiovasc Res. 2004;62(1):74-85. doi:10. 1016/j.cardiores.2004.01.006

24. Sun HY, Wang NP, Kerendi F, et al. Hypoxic postconditioning reduces cardiomyocyte loss by inhibiting ROS generation and intracellular Ca2+ overload. Am J Physiol Heart Circ Physiol. 2005;288 (4):H1900-1908. doi:10.1152/ajpheart.01244.2003

25. Golstein P, Kroemer G. Cell death by necrosis: towards a molecular definition. Trends Biochem Sci. 2007;32(1):37-43. doi:10.1016/j. tibs.2006.11.001

26. Hausenloy DJ, Duchen MR, Yellon DM. Inhibiting mitochondrial permeability transition pore opening at reperfusion protects against ischaemia-reperfusion injury. Cardiovasc Res. 2003;60(3):617-625. doi:10.1016/j.cardiores.2003.09.025

27. Burley DS, Baxter GF. Pharmacological targets revealed by myocardial postconditioning. Curr Opin Pharmacol. 2009;9(2):177-188. doi:10.1016/j.coph.2008.11.009

28. Hausenloy DJ, Yellon DM. Preconditioning and postconditioning: underlying mechanisms and clinical application. Atherosclerosis. 2009;204(2):334-341. doi:10.1016/j.atherosclerosis.2008.10.029

29. Penna C, Mancardi D, Rastaldo R, Pagliaro P. Cardioprotection: a radical view free radicals in pre and postconditioning. Biochim Biophys Acta. 2009;1787(7):781-793. doi:10.1016/j.bbabio.2009.02.008

30. Freixa X, Bellera N, Ortiz-Perez JT, et al. Ischaemic postconditioning revisited: lack of effects on infarct size following primary percutaneous coronary intervention. Eur Heart J. 2012;33(1):103-112. doi:10.1093/eurheartj/ehr297

31. Hahn JY, Song YB, Kim EK, et al. Ischemic postconditioning during primary percutaneous coronary intervention: the effects of postconditioning on myocardial reperfusion in patients with ST-segment elevation myocardial infarction (POST) randomized trial. Circulation. 2013;128 (17):1889-1896. doi:10.1161/CIRCULATIONAHA.113.001690

32. Limalanathan S, Andersen GO, Klow NE, Abdelnoor M, Hoffmann P, Eritsland J. Effect of ischemic postconditioning on infarct size in patients with ST-elevation myocardial infarction treated by primary PCI results of the POSTEMI (POstconditioning in ST-elevation myocardial infarction) randomized trial. $J$ Am Heart Assoc. 2014;3(2): e000679. doi:10.1161/JAHA.113.000679

33. Huffmyer J, Raphael J. Physiology and pharmacology of myocardial preconditioning and postconditioning. Semin Cardiothorac Vasc Anesth. 2009;13(1):5-18. doi:10.1177/1089253208330709 
34. Headrick JP, Lasley RD. Adenosine receptors and reperfusion injury of the heart. Handb Exp Pharmacol. 2009;(193):189-214.

35. Ovize M, Baxter GF, Di Lisa F, et al. Postconditioning and protection from reperfusion injury: where do we stand? Position paper from the working group of cellular biology of the heart of the European society of cardiology. Cardiovasc Res. 2010;87(3):406-423. doi:10. $1093 / \mathrm{cvr} / \mathrm{cvq} 129$

36. Jang Y, Xi J, Wang H, Mueller RA, Norfleet EA, Xu Z. Postconditioning prevents reperfusion injury by activating delta-opioid receptors. Anesthesiology. 2008;108(2):243-250. doi:10.1097/01.anes.000029 9437.93898.4a

37. Penna C, Rastaldo R, Mancardi D, et al. Post-conditioning induced cardioprotection requires signaling through a redox-sensitive mechanism, mitochondrial ATP-sensitive $\mathrm{K}+$ channel and protein kinase C activation. Basic Res Cardiol. 2006;101(2):180-189. doi:10. 1007/s00395-006-0584-5

38. Landoni G, Zangrillo A, Fochi O, et al. Cardiac protection with volatile anesthetics in stenting procedures. $J$ Cardiothorac Vasc Anesth. 2008;22(4):543-547. doi:10.1053/j.jvca.2008.02.020

39. Bice JS, Baxter GF. Postconditioning signalling in the heart: mechanisms and translatability. Br J Pharmacol. 2015;172(8):1933-1946. doi:10.1111/bph.12976

40. Benter IF, Babiker F, Al-Rashdan I, Yousif M, Akhtar S. RU28318, an aldosterone antagonist, in combination with an ACE inhibitor and angiotensin receptor blocker attenuates cardiac dysfunction in diabetes. J Diabetes Res. 2013;2013:427693. doi:10.1155/2013/427693

41. Khalaf A, Babiker F. Discrepancy in calcium release from the sarcoplasmic reticulum and intracellular acidic stores for the protection of the heart against ischemia/reperfusion injury. $J$ Physiol Biochem. 2016;72(3):495-508. doi:10.1007/s13105-016-0498-0

42. Abwainy A, Babiker F, Akhtar S, Benter IF. Endogenous angiotensin(1-7)/Mas receptor/NO pathway mediates the cardioprotective effects of pacing postconditioning. Am J Physiol Heart Circ Physiol. 2016;310(1):H104-112. doi:10.1152/ajpheart.00121.2015

43. Babiker FA, Lorenzen-Schmidt I, Mokelke E, et al. Long-term protection and mechanism of pacing-induced postconditioning in the heart. Basic Res Cardiol. 2010;105(4):523-533. doi:10.1007/s00395-010-0095-2

44. Ferrera R, Benhabbouche S, Bopassa JC, Li B, Ovize M. One hour reperfusion is enough to assess function and infarct size with TTC staining in Langendorff rat model. Cardiovasc Drugs Ther. 2009;23 (4):327-331. doi:10.1007/s10557-009-6176-5

45. Akhtar S. Cationic nanosystems for the delivery of small interfering ribonucleic acid therapeutics: a focus on toxicogenomics. Expert Opin Drug Metab Toxicol. 2010;6(11):1347-1362. doi:10.1517/ 17425255.2010.518611

46. Akhtar S, Benter I. Toxicogenomics of non-viral drug delivery systems for RNAi: potential impact on siRNA-mediated gene silencing activity and specificity. Adv Drug Deliv Rev. 2007;59(2-3):164-182. doi:10.1016/j.addr.2007.03.010

47. Hotta H, Miura T, Miki T, et al. Angiotensin II type 1 receptor-mediated upregulation of calcineurin activity underlies impairment of cardioprotective signaling in diabetic hearts. Circ Res. 2010;106(1):129-132. doi:10.1161/CIRCRESAHA.109.205385

48. Omidi Y, Barar J, Heidari HR, Ahmadian S, Yazdi HA, Akhtar S. Microarray analysis of the toxicogenomics and the genotoxic potential of a cationic lipid-based gene delivery nanosystem in human alveolar epithelial a549 cells. Toxicol Mech Methods. 2008;18 (4):369-378. doi:10.1080/15376510801891286

49. Omidi Y, Hollins AJ, Benboubetra M, Drayton R, Benter IF, Akhtar S. Toxicogenomics of non-viral vectors for gene therapy: a microarray study of lipofectin- and oligofectamine-induced gene expression changes in human epithelial cells. J Drug Target. 2003;11 (6):311-323. doi:10.1080/10611860310001636908
50. Omidi Y, Hollins AJ, Drayton RM, Akhtar S. Polypropylenimine dendrimer-induced gene expression changes: the effect of complexation with DNA, dendrimer generation and cell type. J Drug Target. 2005;13(7):431-443. doi:10.1080/10611860500418881

51. Jones CF, Campbell RA, Brooks AE, et al. Cationic PAMAM dendrimers aggressively initiate blood clot formation. ACS Nano. 2012;6 (11):9900-9910. doi:10.1021/nn303472r

52. Akhtar S, Yousif MH, Chandrasekhar B, Benter IF. Activation of EGFR/ ERBB2 via pathways involving ERK1/2, P38 MAPK, AKT and FOXO enhances recovery of diabetic hearts from ischemia-reperfusion injury. PLoS One. 2012;7(6):e39066. doi:10.1371/journal.pone.0039066

53. Babiker FA. Pacing postconditioning: recent insights of mechanism of action and probable future clinical application. Med Princ Pract. 2016;25(Suppl 1):22-28. doi:10.1159/000381916

54. Vanagt WY, Cornelussen RN, Baynham TC, et al. Pacing-induced dyssynchrony during early reperfusion reduces infarct size. $J \mathrm{Am}$ Coll Cardiol. 2007;49(17):1813-1819. doi:10.1016/j.jacc.2007.01. 070

55. Benter IF, Juggi JS, Khan I, Yousif MH, Canatan H, Akhtar S. Signal transduction mechanisms involved in cardiac preconditioning: role of Ras-GTPase, Ca2+/calmodulin-dependent protein kinase II and epidermal growth factor receptor. Mol Cell Biochem. 2005;268(1-2):175-183. doi:10.1007/s11010-005-3895-1

56. Babiker F, Al-Jarallah A, Al-Awadi M. Effects of cardiac hypertrophy, diabetes, aging, and pregnancy on the cardioprotective effects of postconditioning in male and female rats. Cardiol Res Pract. 2019;2019:3403959. doi:10.1155/2019/3403959

57. Babiker FA, Hoteit LJ, Joseph S, Mustafa AS, Juggi JS. The role of 17-beta estradiol in ischemic preconditioning protection of the heart. Exp Clin Cardiol. 2012;17(3):95-100.

58. Katakam PV, Jordan JE, Snipes JA, Tulbert CD, Miller AW, Busija DW. Myocardial preconditioning against ischemia-reperfusion injury is abolished in zucker obese rats with insulin resistance. Am J Physiol Regul Integr Comp Physiol. 2007;292(2):R920-926. doi:10.1152/ ajpregu.00520.2006

59. Miki T, Miura T, Hotta H, et al. Endoplasmic reticulum stress in diabetic hearts abolishes erythropoietin-induced myocardial protection by impairment of phospho-glycogen synthase kinase-3betamediated suppression of mitochondrial permeability transition. Diabetes. 2009;58(12):2863-2872. doi:10.2337/db09-0158

60. Labieniec-Watala M, Watala C. PAMAM dendrimers: destined for success or doomed to fail? Plain and modified PAMAM dendrimers in the context of biomedical applications. J Pharm Sci. 2015;104 (1):2-14. doi: $10.1002 /$ jps. 24222

61. Siewiera K, Labieniec-Watala M. Ambiguous effect of dendrimer PAMAM G3 on rat heart respiration in a model of an experimental diabetes - objective causes of laboratory misfortune or unpredictable G3 activity? Int J Pharm. 2012;430(1-2):258-265. doi:10.1016/j. ijpharm.2012.03.037

62. Wan TC, Tosh DK, Du L, Gizewski ET, Jacobson KA, Auchampach JA. Polyamidoamine (PAMAM) dendrimer conjugate specifically activates the A3 adenosine receptor to improve post-ischemic/reperfusion function in isolated mouse hearts. $B M C$ Pharmacol. 2011;11(1):11. doi:10.1186/1471-2210-11-11

63. Farshbaf M, Davaran S, Zarebkohan A, Annabi N, Akbarzadeh A, Salehi R. Significant role of cationic polymers in drug delivery systems. Artif Cells Nanomed Biotechnol. 2018;46(8):1872-1891. doi:10.1080/21691401.2017.1395344

64. Xue HY, Liu S, Wong HL. Nanotoxicity: a key obstacle to clinical translation of siRNA-based nanomedicine. Nanomedicine. 2014;9 (2):295-312. doi:10.2217/nnm.13.204

65. Zhang L, Zhu K, Zeng H, et al. Resveratrol solid lipid nanoparticles to trigger credible inhibition of doxorubicin cardiotoxicity. Int J Nanomedicine. 2019;14:6061-6071. doi:10.2147/IJN.S211130 


\section{Publish your work in this journal}

The International Journal of Nanomedicine is an international, peerreviewed journal focusing on the application of nanotechnology in diagnostics, therapeutics, and drug delivery systems throughout the biomedical field. This journal is indexed on PubMed Central, MedLine, CAS, SciSearch ${ }^{\mathbb{B}}$, Current Contents ${ }^{\mathbb{B}} /$ Clinical Medicine, $^{2}$
Journal Citation Reports/Science Edition, EMBase, Scopus and the Elsevier Bibliographic databases. The manuscript management system is completely online and includes a very quick and fair peer-review system, which is all easy to use. Visit http://www.dovepress.com/ testimonials.php to read real quotes from published authors. 